\title{
The turn to responsible golf and the roots of golf's light-green movement
}

In Chapters 3 and 4 we described the sea change under way in the golf industry in the post-war years. By the mid-1960s, golf's landscapes had changed in a literal sense: thanks to a combination of powerful synthetic pesticides and powerful terrain-altering machinery, golf was making good on the modernist impulses held by its key spokespeople since it moved across the Atlantic. Yet the social and cultural landscapes surrounding golf were changing as well. On the one hand, television helped disseminate an arguably exaggerated version of what a golf course should look like - creating an aesthetic standard that was (and is) difficult to maintain across the industry as a whole. On the other hand, pesticide critics were assailing the widespread use of chemicals like DDT. In the eyes of some golf industry representatives, this latter development was tantamount to a 'crusade' against the cause of reason; it threatened humankind's Promethean right to manipulate the Earth. As we discuss in full later in the book, concerns about this 'threat' were not unfounded. For example, the early 1970s saw the formation of the EPA in the United States and a ban on the chemical DDT.

But our review of industry trade publications also gives reason to believe that golf industry members themselves were coming to see established practices as decidedly irresponsible. This was the view of agronomist Albert Neuberger, who in 1967 lamented in the Green Section that superintendents were 'plastering' their golf courses with pesticides. It is likewise the synopsis of some present-day representatives of the golf industry who admit that their forbears too easily took to chemicals like chlordane and DDT. To turn towards 'responsible golf' is to position golf industry representatives as conscientious stewards of the Earth. Or, said another way, it is to adopt a 'light-green' sensibility.

Our contention in this chapter is that the golf industry, facing an emboldened environmental movement, transitioned from a (mainly) Promethean position to a (mainly) ecological modernist one - what we term 'responsible golf' - beginning in the late 1970s. The main mechanism by which ecological modernization (EM) was achieved was the adoption of evermore 
sophisticated - which is to say, formalized and technology-aided - forms of course development and maintenance. Systems such as IPM were adopted from the agricultural sector as a way of addressing golf's purported dependence on chemical treatments. Precision irrigation also became de rigueur. In both cases, the golf industry could stress that changes were indeed taking place in defiance of its 'irresponsible' (recent) history. Moreover, these changes were underpinned by burgeoning research programmes led by organizations such as the USGA and the GCSAA. While recognizing its merits, we conclude this chapter by problematizing golf's 'responsible' turn in a manner that reflects existing criticisms of EM.

\section{From shotgun to rifle shot: IPM and the targeting of golf course pests}

The transition towards ecological modernization - and with it, responsible golf that we are concerned with in this chapter is perhaps best shown by contrasting two articles focused on pesticides from the GCSAA publication Golf Course Management. The first was described in Chapter 3. Entitled 'Golf course chemical warfare takes to the air', this article from 1967 suggested that helicopter-aided DDT spraying might be a highly efficient way of tackling pest problems, and one that could replace mist blowers or hydraulic sprayers (Anon., 1967). This is presumably the type of initiative Albert Neuberger had in mind when reflecting on the 'plastering' of golf courses with synthetic chemicals. The second article came a decade later. Entitled 'Turf insect control programs changing from shotgun to rifle shot', the message was that superintendents could no longer indiscriminately spray their courses, despite their mandate to keep their golf courses green. "It comes down to better identification of the insect causing the problem, selection of the proper insecticide for its control and precise adherence to proper application standards to ensure control at the lowest cost" (Anon., 1977: 17). Pests, in other words, were to be dealt with as isolated problems, though notably the combat metaphor from decades past remained. The 'burden' of knowing how to accomplish this fell to the superintendent (Anon., 1977: 17).

In hindsight, we know that this contrast actually speaks to a wider transition under way in the North American golf industry when it comes to the use of pesticides: a transition towards the adoption of IPM as an industry 'best practice'. It is likely not surprising that golf took cues from other sectors in adopting IPM, 
considering how innovations in agriculture had informed golf course maintenance practices over time.

The history of IPM is traceable to the 1950s, and to the pragmatic concern of entomologists that, in one sense, pests were developing resistance to the chemicals designed for their elimination, and, in another, that non-targeted insects were suffering by way of too-liberal pesticide applications. Peshin et al. (2009) add that, by the early 1960s, "Silent Spring also got the attention of the scientific community on negative externalities of pesticide use" (Peshin et al., 2009: 2). Entomologists thus turned their attention in the scientific literature at this time towards ways of redressing this chemical dependence. It is here that the notion of integrated control was popularized - integrated in the sense that chemical applications are brought together with other mechanisms that serve the cause of regulating pest populations. Kogan (1998) acknowledges that practical awareness of the multifaceted nature of pest management surely preceded these contributions to the literature. Hoskins et al. (1939), for example, argued that nature has its own biological means of controlling pests, and that chemical insecticides should accordingly be used as infrequently as possible (see Kogan, 1998: 244). Even Leland O. Howard's bombastic essay on 'The war against insects', highlighted in Chapter 3, stressed that biological controls could help in the fight against humankind's greatest foe. Nonetheless, in the post-war years pesticide dependency became a greater source of consternation.

Indeed, after debates in the 1960s as to whether 'integrated control' or 'pest management' was the best term for characterizing society's (changing) relationship with unwanted pests, in the 1970s the terms were brought together. The Council on Environmental Quality in the United States prepared a report in 1972 entitled Integrated Pest Management. By this point, Kogan (1998) recounts, there was fundamental agreement that:

1. 'integration' meant the harmonious use of multiple methods to control single pests as well as the impacts of multiple pests; 2 . 'pests' were any organism detrimental to humans, including invertebrate and vertebrate animals, pathogens, and weeds; 3. IPM was a multidisciplinary endeavor; 4. 'management' referred to a set of decision rules based on ecological principles and economic and social considerations. (Kogan, 1998: 247-248)

These tenets have evidently stood the test of time, with the multi-method nature of IPM remaining perhaps its most important characteristic. In controlling pests, Boyd writes, "IPM combines biological pest control (introducing natural enemies or diseases of pest), cultural pest control (e.g. patterns of planting), 
genetic pest control (using pest-resistant varieties), and, as a last resort, chemical pest control (using the lowest quantity and toxicity possible)" (Boyd, 2003: 119). Manual or mechanical control, such as excising weeds by hand, can be considered an IPM tactic as well.

Whether chemicals are indeed a 'last resort', as Boyd describes, has been questioned in recent years, and is a point we return to below. Regardless, since the 1970s, IPM has built institutional support on its academic foundations. For example, in 1996 IPM was enshrined in the Food Quality Protection Act, which stated that "Federal agencies shall use integrated pest management techniques in carrying out pest management activities and shall promote integrated pest management through procurement and regulatory policies, and other activities" (cited in Beyond Pesticides, n.d.: 4). Most importantly for these purposes, IPM was also embraced by the golf industry in North America.

An early mention of IPM in the GCSAA publication Golf Course Management comes in 1979 in an article entitled 'IPM. An alternate approach to solving pest problems' (Bowen et al., 1979). The title of this contribution is telling, as it signals through the qualifier 'alternate' that IPM was far from the hegemonic approach to course maintenance at the time. The text that followed suggested that IPM was nonetheless a worthwhile and timely endeavour:

The phenomenal success of such chemicals as DDT, Lindane and Dieldrin in controlling the insect problems of turf led to their early adoption by professional turf managers and homeowners ... In recent years, the concerns of environmentalists and professional pest control specialists have led to stricter government regulations on the use of pesticides and to renewed interest in alternate pest control strategies. IPM is perceived by some as the proper alternate approach to solving pest problems. (Bowen et al., 1979: 16)

The change in tone from articles in this same publication described in Chapter 3 is unmistakable: environmentalists are referred to in far less hostile terms than before. This same article also provided a definition of IPM that coincides with the multi-method approach described above.

In the Canadian superintendent publication GreenMaster, an early encounter with IPM's conceptual underpinnings comes in a 1977 article advocating the use of pesticide alternatives. This was deemed an 'environmentally clean' solution to pest problems, as well as one that was needed given that insects had starting "liking the pesticides" (Steklasa, 1977: 2). The year 1978 brought further support of IPM-like tactics - if not yet IPM itself. This was accompanied by a rather frank assessment: 
protection of the environment is here to stay - and really in our hearts - can we truly justify the use of long lasting, stable pesticides for non crop production in the proximity of heavily populated areas without really knowing what the long-term effect of those pesticides is going to be? (Pick, 1978: 4)

Indeed, with the arrival of the 1980s, the pro-IPM perspective was articulated with candid - at least by historical standards - reflections on the status quo in golf course maintenance. A 1981 article in Golf Course Management lamented the obsession in golf with 'pretty' courses, and the costs and consequences of maintaining this aesthetic (e.g. inadvertent chemical 'run-off' - Parascenzo, 1981). That this submission was called 'The times they are a-changing' is suggestive of a turn away from the standard set by the famed Augusta National course - or at least that such a turn was desirable. In 1983, the regular 'Thinking Superintendent' column in Golf Course Management was given the subheading 'Spray with restraint'. "There is a logical way of fighting pests with pesticides," the magazine's readership was told, "and that is to do so with some discretion" (Williams, 1983: 78). Again, consider the novelty of such an assertion against the image of helicopter-aided DDT spraying from years past. The April 1983 issue of this same publication offered yet another detailed, and discernibly pedagogical, review of IPM. The approach is not aimed at eliminating pesticides, it was made clear, but rather at flexibility: "[IPM] is a concept that uses more than one tactic to keep pest problems below levels that cause economic, aesthetic or functional turfgrass injury without creating a personal hazard to man, his environment or non-targeted forms of life" (Sherman et al., 1983: 45).

IPM was therefore gathering steam, at least in terms of its promotion in trade publications. Following on from initial descriptions of its principles, the late 1980s and 1990s were a time for success stories in industry publications on golf's adoption of this integrated system. In 1988, agronomist John Foy historicized IPM in the pages of the Green Section. Before the Second World War he wrote, "Man was fighting a losing battle against weeds, diseases, and insects because brute force could not win over sheer numbers" (Foy, 1988: 9). Chemicals such as 2,4-D and DDT changed the equation, and by 1971 US producers were churning out 1.1 billion pounds of pesticide material annually. Yet while insisting that pesticides remained crucial in sustaining established standards of living, Foy also named Rachel Carson specifically in noting the rising fear over 'uncontrolled' chemical uses. The best response in turn was IPM - a systematic way of confronting pest concerns, and one successfully deployed at Sea Island Golf Club in the state of Georgia to cope with a longstanding mole 
cricket problem. Sea Island, in other words, bridged the gap between IPM theory and practice.

Further to the south, in 1995 the course Collier's Reserve was said in Golf Course Management to be "state-of-the-art from the start", in part because IPM (here referred to as integrated plant management) was thoroughly suffused through Collier's course maintenance philosophy (Anon., 1995a). It was not long before the GCSAA published a book-length overview of IPM and its relationship to golf (Schumann et al., 2002). This included 'portraits' of regionally specific IPM practices. Florida superintendent Darren Davis wrote: "All of the pesticides applied at Olde Florida Golf Club are on a curative basis. Preventive application of herbicides, insecticides, nematicides, or fungicides are not done" (Davis, 2002: 223, emphasis in original).

\section{Science, technology, and the new modern superintendent}

The GCSAA's IPM Handbook for Golf Courses stressed that IPM is also a scientific enterprise. Indeed, as IPM became more prominent towards the end of the millennium, the golf industry was moving further and further away from Leonard Macomber's assessment from nearly a century earlier that botany, among other branches of science, is apt to prove highly confusing for golf superintendents - a view described in Chapter 3. A notable IPM 'success story' in Golf Course Management from 1987 on Sherman Hollow's golf course in Vermont noted the importance of measurement and monitoring to the successful implementation of an IPM system. In an inset to the article, penned by GCSAA Manager of Government Relations, Zachary Grant, superintendents were told they need to know, for example, the ratio of grubs to square footage on their courses so that they could, in turn, apply chemicals once an 'unacceptable' threshold had been crossed - and only once it had been crossed. Prior to that point, non-chemical means of control could be used. IPM was thus described as context-dependent: "As long as you know how many grubs can be allowed per square foot before treatment on your course, there is no need for an industry standard" (Grant, 1987b: 10, emphasis in original). In devising their own pesticide use plan, the Sherman Hollow management team consulted a number of authorities, including a hydrogeologist, toxicologist, agronomist, and environmental scientists. In a sign of how regulators would come to see pesticide usage on golf courses, the EPA was also enlisted to help with the operation of IPM (Grant, 1987a).

Apart from specific initiatives of this kind, the rise of IPM was accompanied by - and perhaps itself inspired - interest from golf industry members in 
bolstering their organizational research agenda. This is not to say the cause of research was new - for example, the GCSAA's Scholarship and Research Fund was founded in 1955 (GCSAA, n.d.a.). Instead, it is to say that research increasingly articulated with the perceived need for environmental responsibility. In the 1980s, the USGA and GCSAA combined forces to develop a formalized and robust Turfgrass Research Program. As written in the pages of Golf Course Management in 1985: "The objectives of the Turfgrass Research project are clear and simple to state: it is our goal to develop new grasses that will use 50 percent less water and require 50 percent less maintenance cost" (Anon., 1985: 19). By 1991, James T. Snow, National Director of the USGA Green Section publication, reflected fondly on what had been accomplished through this programme during its short history. He also described another initiative of this kind: the USGA's Environmental Research Program. Following a thorough review of the scientific literature in the early 1990s, this latter initiative was oriented around three key areas: the fate of pesticides and nutrients on golf courses; 'alternative' (which presumably meant non-chemical) methods of pest control; and the impacts of golf on people, wildlife, and the environment. Snow also noted that the USGA had allocated $\$ 2.8$ million to fund environment-related research projects: "It is anticipated that this three-year study will produce a much greater understanding of the effects of golf course activities, including pesticide and fertilizer applications, on people, wildlife, and the environment" (Snow, 1991: 12).

The story was much the same in Canada. The Canadian Turfgrass Research Foundation (CTRF) was founded in 1967, and given charitable status by the federal government a decade later. It was administered by the Canadian Golf Superintendents Association (CGSA) until 1992, at which point control was passed to Golf Canada (CGSA, n.d.c). Regional organizations such as the Atlantic Turfgrass Research Foundation Inc. and the Ontario Turfgrass Research Foundation also emerged to complement the CTRF as time passed (AGSA, n.d.; Jiggens, n.d.). The main point here, however, is that the promotion of responsible golf, as in America, involved both touting IPM and professing the importance of research. In 1991, for example, IPM's multifaceted approach was compared to how a doctor might prescribe lifestyle, dietary, and medical remedies all at once (Fushtey, 1991). In the same year, GreenMaster reported CGSA President Ken Olsvik's view that, when it comes to the environment, "association policy and decisions have to be based on scientific data and that is why the CGSA is placing a high priority on promoting and supporting research" (Mellersh, 1991: 19).

Science, precision, responsibility: these were the new shibboleths of the golf industry as Rachel Carson's Silent Spring drifted further and further into the 
past. With the literature on EM in mind, it is not surprising that technologies grew evermore important in precision course management as well.

Computers are one case in point in this regard. In 1992, environmental scientist Kevin Franke described the Leaching Estimation and Chemistry Model (LEACHM), among other computer simulation programmes, as a useful development for golf course management. LEACHM alone would not produce an IPM plan, Franke wrote in the pages of the USGA's Green Section: "What LEACHM will provide is a determination of what, where, and when products can be expected to work efficiently and safely" (Franke, 1992: 19). Three years later, in an article entitled 'IPM, monitoring, and management plans', computer simulations were likewise discussed as useful in predicting the fate of pesticides in the environment. This in turn could help in selecting appropriate chemicals for use on the golf course (Peacock and Smart, 1995). In similar fashion, and with a new millennium nearing, Golf Course Management announced in 1999 the arrival of 'The computer age. The magazine's readership was told that superintendents were increasingly adopting computer software programmes to help with everything from personnel files to fertilization scheduling to the irrigation of their courses (Goodman, 1999).

Indeed, as much as pesticides and pesticide backlash were concerns from the late 1970s onwards, so too did golf's demand on water supplies attract much attention in industry publications. In 1981, it was announced in Golf Course Management that the 1980s would be the 'water decade' (Rosillon, 1981: 35). A year later, the problem of overwatering turfgrass was described in the provocatively titled article, 'Does your irrigation system know there's a water crisis?' (Augustin, 1982). In this same year, the article 'Game plan for golf' came to similar conclusions about the pressing need to adopt a responsible approach with respect to course irrigation (Anon., 1982a). The outlook in this case, however, was also optimistic in the sense that science and technology could carve out a suitable - which is to say, sustainable - pathway forward. The Allied Associations of Golf, an organization that included, among others, the USGA, the GCSAA, and the American Society of Golf Course Architects, had settled on a multifaceted approach for the future:

The priorities are, in order, reducing significantly the need for potable water on turfgrasses; developing grasses that will adapt to brackish, recycled or otherwise marginal-quality water; improving water utilization of turfgrasses; developing grasses that require minimal maintenance and are pest resistant, winter-hardy and traffic tolerant, and improving grass varieties through modern scientific methods. (Anon., 1982a: 71)

In a similar vein, the President's Message in the September/October 1988 issue of GreenMaster called attention to recent water shortages in Canada. "As turf 
managers," GCSA President Barry Britton urged, "we have to re-evaluate our watering methods and also update and fine-tune our irrigation systems so that our client, 'the golfer', has good golfing conditions available to him" (Britton, 1988: 6). In 1993, it was said that computerized irrigation both saves resources and cuts expenses. "Using the lack of water as a rallying cry, environmentalists have reasoned that golf course facilities waste water and shouldn't be built in arid regions, leaving developers out to dry." But, the article continued, "That scenario may be changing, thanks to computerized irrigation systems that save both water and energy" (McWhirter, 1993: 29).

\section{Responsible golf in the new millennium}

With the arrival of the new millennium, the trends described above showed no signs of abating. The 2000s brought increased discussion of another, even more robust turf management system: Best Management Practices (BMPs). In 2005, professor and turfgrass physiologist Robert N. Carrow was flanked by Ron R. Duncan, a retired professor and vice president of Turf Ecosystems LLC, and David Wienecke, a director of golf course maintenance at a course in California, in espousing the merits of BMPs. Indifference or inattention to environmental matters was no longer a viable option, the authors averred, for since the publication of Silent Spring, "societal pressures have increasingly moved toward national regulatory action to protect various aspects of the environment" (Carrow et al., 2005: 81). The two pathways remaining were those of 'rigid regulation' and 'holistic, science-based methods' - note the implication of mutual exclusivity. As might be expected, the authors favoured the latter. BMPs were positioned as similar to IPM in that they take an holistic, science-based approach to managing the golf course environment. The focus on BMPs, however, allows for a wider view, one considerate of, for example, water conservation alongside other environmental 'flashpoints' such as pesticides. Altogether, as Carrow and his colleagues explained, BMPs favour a scientific approach to environmental management whereby 'inputs' are applied to the golf course only as needed, and whereby new technologies are actively welcomed in the process of (re)imagining 'best practices'. This was deemed far more preferable than 'rigid regulations' based on politics rather than science: "The latest concepts and technology can be effectively applied to environmental problems, but political or personal beliefs that are not based on good science cannot" (Carrow et al., 2005: 82). As we shall in the next chapter, this 
was neither the first nor last time that golf's close relationship with science was emphasized in the context of discussing environmental policy.

Perhaps an even more important development for golf superintendents in the early 2000s came when the long-established research and education funding arm of the GCSAA changed its name to the Environmental Institute for Golf (EIFG). The integration of environmental awareness into the golf superintendent profession was by no means an overnight phenomenon, as we have seen. But with the arrival of the EIFG, golf's professed 'green' sensibilities were privileged more so than ever before. To be specific, golf's embrace of sustainability was emphasized with newfound intensity. The GCSAA now directly recounts the Brundtland Commission's definition of sustainable development on its website, while also situating itself as an organization that is indeed concerned with the 'triple bottom line':

The US golf industry recognizes sustainability as the integration of environmental stewardship, social responsibility and economic viability as a critical and never-ending goal. The golf industry embraces sustainability as "meeting the needs of the present without compromising the ability of future generations to meet their own needs". (GCSAA, n.d.b., emphasis in original)

In 2006, the EIFG set out on perhaps the most significant research endeavour in the GCSAA's history - one described as 'groundbreaking' by the organization itself (GCSAA, n.d.c.). The Golf Course Environmental Profile was designed to collect baseline data on environmental performance at golf courses across the country. It specifically featured five surveys, each with their own respective focus: (a) property profile and environmental stewardship of golf courses; (b) water use and conservation practices; (c) nutrient use and management; (d) energy use and conservation practices; and (e) pesticide use on US golf courses. The famed golfer and EIFG advisory council chair Greg Norman said in the foreword to the first report: "Thanks to a growing amount of data, the golf industry is able to state with even greater confidence that golf courses can be compatible with the environment" (GCSAA, 2007: 6).

Importantly, it is not the GCSAA alone that has devised and actively extolled the merits of such endeavours. The USGA's environmental research programme marches forward. Like the GCSAA, the USGA harbours the perspective that environmental sustainability and economic solvency are by no means incompatible (see USGA, 2009). For their part, the American Society of Golf Course Architects - allies of the GCSAA at least since the aforementioned Allied Associations of Golf was formed - shares many stories online of golf courses 
serving the cause of environmental sustainability. These often crystalize around the reconfiguration of environmentally damaging landscapes such as manufacturing plants and landfills to make them more in touch with nature (see American Society of Golf Course Architects, n.d.). Indeed, in Chapter 6 we explore the golf industry's simultaneous promotion of golf course management as a technological wonder and of golf courses themselves as pristine, natural spaces.

In Canada, IPM is still positioned by the CGSA as a 'sustainable approach', one "combining biological, cultural, physical, and chemical methods to manage pests so that the benefits of pest control and turf health are maximized and the health and environmental risks are minimized" (CGSA, 2007a; CGSA 2007b). The National Allied Golf Associations - an umbrella organization that includes Golf Canada, the CGSA, and the Canadian Professional Golfers Association, among others - has also emerged to actively profess golf's support of research in the interest of finding ever more effective products and management practices that go towards the reduction of environmental risks (see NAGA, 2009). And though we have not analysed the historical trajectory of environmental management in the UK to the same extent, key governing bodies across the Atlantic now advocate a similarly responsible position. As the R\&A, a key UK-based governing body, tells golf industry representatives, "As a user of natural resources, you have a responsibility to operate in a manner which shows concern and awareness for environmental issues" (R\&A, n.d.a.). ${ }^{1}$ As in the USA and Canada, they too stress that water and pesticides need be used discriminately (e.g. with the help of precision technologies), and that water should be deployed in effluent form when possible (R\&A, n.d.b.; R\&A, n.d.c.). 'Spray with restraint' and, evidently, 'water with restraint' are now creeds on both sides of the Atlantic.

\section{EM and its discontents: troubling 'responsible golf'}

The aforementioned 'Game plan for golf' article appearing in Golf Course Management in 1982 is telling for more than just its description of looming technological and scientific endeavours. The changed perception of the environment in this submission compared to years' past is noteworthy as well. The opening lines of this article read as follows:

Nothing on earth is permanent. Our world is in a constant state of change, and obsolescence results from an inability to adapt to that change. In fact, our survival is predicated on our ability to keep up with and adjust to the change going on around us. (Anon., 1982a: 71) 
Compare this frank admission to GCSAA President Richard C. Blake's statement on a similar matter from just eleven years earlier:

The truth of the matter is that civilization did not begin until man learned to use fire and other tools to modify his environment. In other words, the fate of the human race and the wildlife that has shared in its rise rests on man's ability to anticipate, modify, and control environmental changes. (Blake, 1971: 7, emphasis in original)

Ecological modernization, as said in Chapter 2, is as much dependent on a particular perception of humankind's relationship with the environment as it is the adoption of sustainability-driven technological initiatives. The comments in the second passage above are truly Promethean in both tone and content. Blake near-literally recounts the Promethean myth through reference to man's adoption of fire for the sake of environmental control. By contrast, the passage from 1982 admits that environmental change transcends humankind. It is undoubtedly humbler in this regard.

At the same time, however, rather than urging demodernization (e.g. the adoption of more precautionary course management techniques that are informed by a recognition of the limits of human-driven innovations, technologies, and the 'latest science') when confronting the realization that 'nothing on Earth is permanent', the solutions posited in the 'Game plan for golf' specifically, and in the pages of trade publications in general, in our view remain anthropocentric. That is to say, they see human-led scientific and technological endeavours - whether the development of more resilient turfgrass, precision irrigation, 'rifle shot' pesticide applications through IPM, or other, similar initiatives of this kind - as vehicles for manipulating the Earth, albeit with care.

Thus, after defensiveness in the immediate post-Silent Spring years, golf moved to a 'responsible', light-green approach to environmental management thereafter. With this change, the combat metaphor for managing pests was no longer applicable in the way it once was. A more apt metaphor was evinced by golf architect Mike Hurdzan in a recent interview in the publication Golf Digest. Hurdzan's response to the question, 'Do you think the pesticides used on golf courses today are safe?' was as follows:

I do. They've got to be properly used. It's a very fine line between a medicine and a poison - we're trying to walk that line, to treat a pesticide as a medicine to get rid of these pests that are causing us a problem, but if we abuse them, then they can be poisons. The proper use of pesticides presents no problems at all. (Barton, 2008) 
We saw above how IPM was compared in Canada to the way a doctor prescribes multiple remedies. The medical metaphor is a neat conduit for the principles the golf industry had come to stand for in the 1980s and beyond: efficiency, precision, erudition, and, above all, responsibility.

But while our above presentation of results suggests an easily discernible, linear narrative, and while proponents of responsible golf have recounted such a narrative as well, our findings on the North American golf industry's adoption of environmental responsibility are in fact more complex. That is to say, the narrative is disrupted by contradictions lying in golf's adoption of scientific research and technological ingenuity in developing their 'green(er)' sensibilities. Below we identify two particular issues related to the formalized systems associated with responsible golf. These issues reflect critiques of ecological modernization in general.

A first contradiction pertains to the certainty with which claims have been made - and continue to be made - by the golf industry about the risks associated with established golf course maintenance practices. Responsible golf rests on the premise that, while chemical uses should be reduced where possible, research has proven pesticides non-threatening and effective when applied according to label specifications. Indeed, this premise is built in to the principles of IPM. The response of pesticide critics has primarily been to stress that this organizational disposition is not precautionary enough. Pesticides, even when deployed in small quantities, might have toxic effects overlooked in research, might accumulate in the environment, or might have synergistic effects when encountering other chemicals (e.g. see Arya, 2005). Environmental activist Jay Feldman, director of the organization Beyond Pesticides, made many of these points in 2008 in the same Golf Digest article from which Hurdzan was quoted above:

You'll hear golf course superintendents say, 'We're using such minuscule amounts of these chemicals.' But endocrine disruption can happen at really low exposures. We don't even have the testing protocol to assess this low dose ... With pesticides, we're not just dealing with what we do know, but also what we don't know. The risk-assessment protocol is filled with wrong assumptions. One example is the story of chlorpyrifos, whose trade name is Dursban, which was banned from household use in 2000 because of neurological effects. It had been widely used for insect control indoors and outdoors. But it's still used in golf. (Barton, 2008)

Criticisms of this kind tacitly implicate IPM, given that this integrated system ultimately allows for the continued use of pesticides at the applicator's discretion. It is perhaps unsurprising, then, that many environmental activist groups have urged that IPM is unsatisfactory as an environmental management system 
when it comes to the cosmetic (i.e. non-essential) use of pesticides. As the Canadian Cancer Society told the British Columbia provincial government in recent hearings over a potential cosmetic pesticide ban, IPM sounds reasonable on the surface, though in principle its tenets are vague and open to interpretation (Kaminsky and Seely, 2011; also see West Coast Environmental Law, 2011). A representative from the Canadian Association of Physicians for the Environment made a similar point in an interview for this research:

We don't think IPM protects public health - I mean that's really the long and the short of it ... I think IPM was essentially devised by industry to keep spraying. I mean at the end of the day, IPM allows you to keep spraying for non-essential purposes so we don't support IPM. (Personal interview, February 2012)

Yet, as noted, the first contradiction with which we are concerned pertains more to the defence of chemicals than their sustained use, though these are certainly related points. Specifically, what a historical analysis reveals is that the golf industry's present-day defence of chemicals is far from new. Some pesticides that are now widely discredited - at least when it comes to cosmetic uses - were once defended by industry representatives using familiar rhetorical techniques. For instance, in 1970 the publication Golf Course Management featured an article written by a representative of the turf industry suggesting that concerns about the negative impacts of chemicals such as DDT and mercury were ill-founded. Among the arguments made at this time was that the latest science was 'on the side' of continued pesticide use: "Scientists ... who have been working with pesticides have concluded that there is no evidence that pesticides directly cause any disease" (Kerr, 1970: 28). In this same year, the GCSAA's Director of Education contended that concerns about DDT poisoning were tantamount to "pure, unadulterated and sensationalistic reporting." He added: "We need to work with facts and reason; not with protests and superficial knowledge" (Alexander, 1970: 20; also see Van Buskirk, 1971). In this way, golf was on the side of reason and logic, while pesticide critics were swayed by emotion.

DDT is not alone as a chemical for which the passage of time has not been entirely kind. In 1970, Gord Witteveen, then the newly elected president of the Canadian Golf Course Superintendents Association, supplied an unwelcoming assessment of a potential ban on mercuries and arsenicals: "I don't know how we can work without them ... there are very few substitute chemicals available" (Marks, 1970: 45). In 1988, the GCSAA noted that their advocacy efforts engendered a legislative exemption for the use of cadmium fungicides on golf course greens, tees and aprons (Anon., 1987a). These two cases can be 
set against the more reflexive assessments of recent times. Golf course architect Mike Hurdzan said in the same Golf Digest article noted above: "Back in the mid-'50s we were using cadmium, lead, arsenic, mercury; we were using all these heavy metals. We were using farm-grade fertilizers. Well, those things are gone. We didn't know any better back then. Science has showed us a better way to do things" (Barton, 2008). In this same issue, superintendent Jeff Carlson, whom we mention again in later chapters for his work in organic golf, likewise recounted a story of his very negative experience with cadmium-based and mercury-based fungicides in the late 1970s (also see PMEP, n.d.). Another case in point here is the chemical 2,4,5-T, for which we find support in a 1984 Golf Course Management article saying this product is backed by an extensive safety record (though an editor's note clarified that this was the author's own opinion - Baskin, 1984). Not long after, use of 2,4,5-T was halted in both Canada and the United States.

Still another example lies in the case of the insecticide diazinon. As Wheeler and Nauright (2006) recount, it was banned from usage on golf courses in 1990, following a five-year legal dispute, and in light of evidence that it was poisoning birds. What our review of industry trade publications reveals is that Ciba-Geigy Corp., reported in the late 1980s to be the main supplier of diazinon-based products in the USA at the time, credited the support they received from the GCSAA - and, more specifically, the testimony of golf superintendents - in winning a 1988 legal decision to allow diazinon's sustained use (Anon., 1988d).

Of course, science improves and knowledge changes. Hurdzan makes this point. But a historical analysis suggests that, over time, the golf industry has in many cases effectively known the answer - pesticides pose no considerable threat before the question is even asked. The fact that chemicals still used on golf courses such as 2,4-D remain a source of consternation for many researchers and activists, as discussed in our introductory chapter, stands out even more in light of this historical analysis. It is relevant here too that the depiction of pesticide criticism as based in emotion continued beyond the 1970s as well. In 1982 it was said in Golf Course Management that a small but vociferous group of activists were disregarding science in favour of anti-pesticide ideology and politics (Arnold, 1982: 45; also see Charters, 1989). And though relations with activists improved in the 1990s (as we discuss in the following chapter), concerns about emotional, rather than rational, anti-pesticide pleas did not disappear (e.g. see Langley, 1998).

The question of why a generally pro-pesticide perspective, as opposed to a more precautionary one, has remained in the age of responsible golf is a complex one. It is important to remember that Augusta National syndrome has yet to be 
'cured', as discussed in Chapter 4, and so individual superintendents must still reckon with a lofty 'green' standard.

Yet if we return to the comments made by activist Jay Feldman in Golf Digest, the close affiliation between the golf and chemical industries should also be taken into account. In Chapter 3 we noted the concern occasionally expressed in trade publications in the 1960s and 1970s over 'Satchmo', the pesticide vendor with a satchel of magical (read: untrustworthy) elixirs. But, as Feldman notes, over time chemical suppliers have formed a bond with golf course chemical applicators, at least at an organizational level. In one sense, therefore, trade publications such as GreenMaster and Golf Course Management have served as venues for chemical companies to advertise their products, thus allowing direct communication on the merits of pesticides with those who might use them. In another, perhaps even more significant sense, chemical companies have also become leading donors to the aforementioned Environmental Institute for Golf (EIFG) - a matter for which, to their credit, the GCSAA is clearly transparent. The chemical company Syngenta, for example, is in the 'Victory Club' of donors, having pledged over $\$ 1$ million towards matters like research, educational initiatives, and scholarships. Bayer Environmental Science, another pesticide supplier, is listed in the 'Star Club' $(\$ 500,000-\$ 999,999)$ while other, similar companies such as Dow AgroSciences and the Monsanto Company have pledged support as well (GCSAA, n.d.d). In Feldman's words: "The chemical companies always have their hand in the trade associations ... And because of this, it becomes a pro-pesticide industry" (Barton, 2008). Indeed, our point here is not that EIFG-sponsored research is necessarily invalidated by these affiliations; it is instead that with this 'golf-chemical complex' in place, it is unsurprising that the golf industry has arrived at a position whereby chemicals can at best be reduced, and are defended almost as a matter of principle.

A second contradiction emerging through our historical analysis pertains to the golf industry's quest for efficiency through the tenets of ecological modernization and its simultaneous pursuit of economic growth through both the popularizing of golf and the development of new courses. The 1990s may well have been a time when 'responsible golf' truly began to flourish. But, as noted in earlier chapters, this decade also brought another 'boom' in course development. The supply of golf courses in the United States grew by roughly 20 per cent in the 1990s, while demand (gauged by rounds played) increased by roughly 15 per cent (Hueber and Worzala, 2010). It is important to say that this substantial uptick in development was not simply the result of individual entrepreneurialism; as noted in Chapter 4, in the late 1980s, the National Golf Foundation (NGF) 
devised a Strategic Plan for the Growth of the Game calling for the development of 'A course a day' in the following decade (Hueber and Worzala, 2010). Hueber and Worzala (2010) note that the 1990s 'boom' also brought the 'marriage' of golf and real estate development, with 60 per cent of courses tied to real estate projects in the United States. The common result, they argue, were courses that brought a high degree of difficulty for players, a manicured aesthetic, and, ultimately, the subsuming of environmental concerns under the maximizing of profit.

The 1990s 'boom' came to an end as the new millennium arrived: the number of rounds played per eighteen-hole equivalent decreased by 9 per cent from 2001 to 2008, yielding "an unhealthy imbalance between supply and demand" (Hueber and Worzala, 2010: 7; also see NGF, 2009). The response, then, might have been to 'purge' golf courses - and in doing so, much of their environmental impact - in the interest of aligning supply and demand. Indeed, Hueber and Worzala quote Joe Beditz, president and CEO of the NGF, as saying, "the problem of oversupply will fix itself once the industry loses some 1,500 to 2,000 golf courses" (Hueber and Worzala, 2010: 8). Yet the golf industry has evidently chosen the opposite tactic: to reinvigorate the popularity of the game through a formal PR programme. In 2000, 'Golf 20/20' was launched by a group of allied golf organizations and stakeholders for this very purpose. Within its remit are initiatives targeting specific demographic groups - for example, youth and women as well as programmes aiming to change the perception of golf in the view of lawmakers and the public in general (a matter we explore further in the following chapter). Organizations such as the GCSAA have also stressed the merits of Golf 20/20 for its membership, including the development of new courses. As said in Golf Course Management (GCM) shortly after this programme's unveiling:

because the goal of Golf 20/20 is to encourage rapid growth of the game's popularity and numbers of participants, superintendents would likely see more job opportunities, both on alternative courses designed for teaching new players, as well as on new, full-size golf courses built to meet rising demand as those players gain enough confidence to take their games to a higher level. (GCM Staff, 2001: 13)

As said in Chapter 3, demand is shown in this case to be an industry construction at least as much as a natural market force.

From an environmental perspective, the optimistic (that is, ecological modernist) view of this ongoing emphasis on economic growth is that it can be offset by heightened efficiencies in, for example, the use of pesticides and water. But the opposite view is equally compelling: that the efficiencies so celebrated by the golf industry are easily counteracted by increases in the amount of terrain requiring 
'treatment' as golf courses are built at a frantic pace (at least in the 1990s). To be sure, it is no surprise to find any given industry actively supporting its own economic well-being. Yet when this same industry is ostensibly driven towards environmental responsibility, a contradiction emerges in the style of Jevon's paradox (described in Chapter 2). That is to say, the pursuit environmental efficiencies exist in a wider context where the need for overall expansion goes unquestioned. Moreover, our critique here does not yet account for the global growth of golf - a point we explore in examining the 'dark-greening' of golf in Chapters 8 and 9.

Taken together, these contradictions unsettle the linear narrative commonly evinced by golf industry representatives in present times - that is, the view that golf has unquestionably moved beyond its brief irresponsible turn in the early post-war years, and has arrived instead at a deeply responsible place. Scientific research and technological innovation are crucial to this light-green disposition: it is effectively an article of faith that science and technology can deliver properly 'green' outcomes while also allowing the golf industry to thrive financially. Said otherwise, whereas the golf industry in North America spent the first three quarters of the twentieth century modernizing its approach to service provision, the last quarter was directed towards a slightly different end: ecological modernization.

But scientific research and technological innovation do not stand alone as articles of faith. A historical analysis suggests that they have been deployed in a context that takes for granted other principles as well: namely, that pesticides cannot be eradicated tout court and that the golf industry must unfailingly grow larger. The point in highlighting these contradictions is not to suggest that science and technology are irrelevant to the pursuit of environmental solutions. In keeping with critiques of ecological modernization, it is to say that there are excellent reasons to be sceptical about situations where science and technology-oriented solutions are presented as the only solutions to environment-related problems. Our own scepticism about unfettered faith in these sorts of solutions becomes quite pronounced as we came to learn about how science and technology were mobilized in defence of practices that history has ultimately deemed 'irresponsible.' As shown in the following chapters, the golf industry has gone to great lengths to stress the value of their responsible practices to lawmakers and the public both.

\section{Note}

1 The name R\&A refers to and derives from, but is separate and distinct from, The Royal and Ancient Golf Club of St Andrews (for details, see http://www.randa.org/en/ RandA.aspx). 